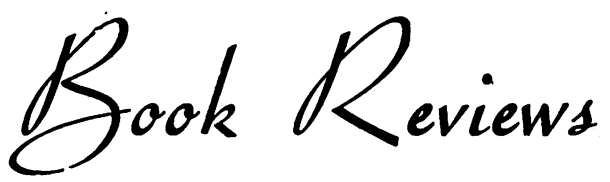

\section{TECHNIQUES AND PROCEDURES OF ANAESTHESIA}

By John Adriani, M.D. Second Edition. Pp. xiv +568 , with $x 94$ illustrations. Oxford: Blackwell Scientific Publications. I956. 66s.

The second edition of 'Techniques and Procedures of Anaesthesia ' by Adriani has been brought more up to date by the addition of descriptions of hypothermic and hypotensive techniques and of techniques using the drugs succinyl choline, pethidene and viadril.

The descriptions of the various techniques are very clear and those dealing with induction of anaesthesia using the gaseous and volatile agents should be especially useful to beginners.

Many of the techniques and the table in Part I dealing with selection of anaesthesia have a decidedly transatlantic flavour.

\section{PROGRESS IN CLINICAL MEDICINE}

Edited by Raymond Daley, M.D., F.R.C.P. and HeNRY Miller, M.D., F.R.C.P. Third Edition. Pp. 4I4, with 36 illustrations. London: J. \& A. Churchill Ltd. 1956. 40s.

This extremely successful book now enters its ninth year, and has reached its third edition. It is well written, carefully edited and excellently produced at a reasonable price, and when it first appeared in 1948 it performed a very real service in introducing a great deal of new work to many postgraduates who had been out of touch with recent developments for some years. This particular requirement, however, is not nearly as great now as it was then, and it seems justifiable to examine the aims and achievement of the present edition much more critically.

One of the criticisms that can always be levelled against a book of this type is that its purpose is never quite clear. Is it intended to serve as a review to help busy practitioners keep up-to-date ? In that case a new edition, appearing after an interval of four years, should contain almost entirely new material. Yet in this one, though we are assured that the text has been completely re-written, only two new sections have been included. Their titles seem to illustrate the editors' uncertainty: they are 'The Care of the Aged ' and ' Radioactive Isotopes.' Each is admirable in its own way, yet one can hardly imagine any practising doctor who will be interested in both. But perhaps the book is meant for the younger man in search of Truth for high examinations? He will find certain parts very rewarding: Dr. de Wardener's section on Renal Disorders, for instance, is a model: accurate, factual and well documented. Yet some are disappointing, judged by this standard: the section on Metabolic Bone Disease, for example, a subject of very great topical interest, is disappointing. What can one make of the statement that 'osteomalacia resulting from nephrocalcinosis is dramatically relieved by the giving of alkalies'? Does the author really mean to imply, on page Ior, that the blood calcium is raised as often in secondary as in primary hyperparathyroidism? The section on the Endocrine Disorders, also, might be expected to contain more precise information. In discussing the diagnosis of Addison's Disease the author ignores the empirical, yet exact and well-tried Robinson-Kepler Test but mentions the vague 'Water-Diuresis Test' with no details at all, while his description of the use of ACTH in the diagnosis lacks precision and the use of the gel is not mentioned. In other places in this section we expect more exact information than we get. Elsewhere, Hypertension might be expected to be dealt with fully and authoritatively, since great advances have been made in the last five years. Yet it is difficult to see how anyone could be helped to the better management of his cases by the study of this section or, indeed, why anyone should want to be, after reading the dismal little paragraph entitled 'How to 'Treat Hypertension.'

Any book, of course, by a team of authors could be criticised destructively in this piecemeal way, and this may be particularly unfair to an established favourite. But surely the time comes in the life of every book on 'Progress' to decide what is its real purpose, and to set even higher standards of accuracy and authority?

\section{OPERATIVE SURGERY \\ Volumes I and II}

Edited by Charles Rob, M.C., M.Chir., F.R.C.S. and RoDNey Smith, M.S., F.R.C.S. Pp. xviii +342 , illustrated, and $\mathrm{Pp}$. xii +407 , illustrated, respectively. London: Butterworth \& Co. 1956. $£ 5$ ros. each.

Text-books of operative surgery are usually remarkably unsuccessful in their attempts to give 